\title{
CoNF-950512--264
}

UCRL-JC-119409

PREPRINT

\section{Emission, Plasma Formation, and Brightness of a PZT Ferroelectric Cathode}

\author{
S. Sampayan, G. Caporaso,
}

D. Trimble, and G. Westenskow

This paper was prepared for submittal to the 1995 Particle Accelerator Conference and International Conference on High-Energy Accelerators

Dallas, Texas

May 1-5, 1995

April 27, 1995

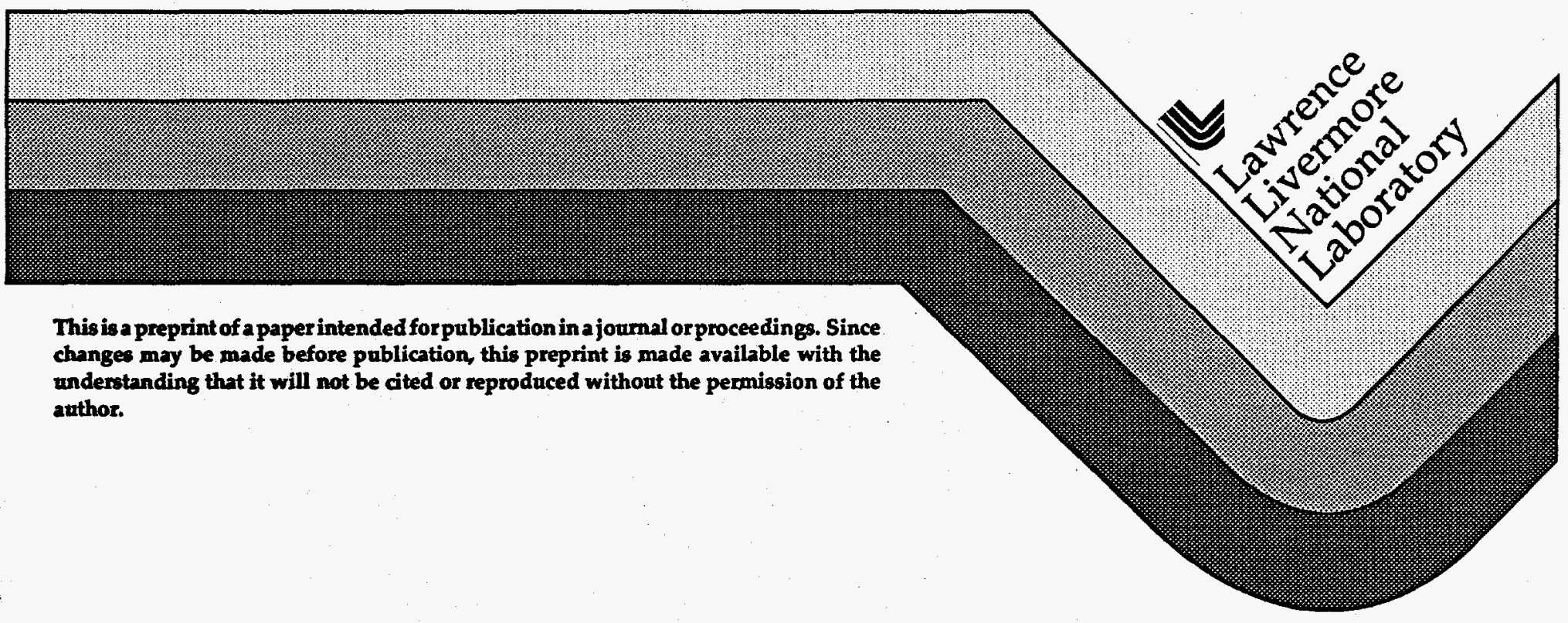

$$
\begin{aligned}
& \text { APCEIVED } \\
& \text { JUL } 251995 \\
& \text { OSTI }
\end{aligned}
$$




\section{DISCLAIMER}

This document was prepared as an account of work sponsored by an agency of the United States Government. Neither the United States Goverrment nor the University of California nor any of their employees, makes any warranty, express or implied, or assumes any legal liability or responsibility for the accuracy, completeness, or usefulness of any information, apparatus, product, or process disclosed, or represents that its use would not infringe privately owned rights. Reference herein to any specific commercial product, process, or service by trade name, trademark, manufacturer, or otherwise, does not necessarily constitute or imply its endorsement, recommendation, or favoring by the United States Government or the University of California. The views and opinions of authors expressed herein do not necessarily state or reflect those of the United States Government or the University of California, and shall not be used for advertising or product endorsement purposes. 


\section{DISCLAIMER}

Portions of this document may be illegible in electronic image products. Images are produced from the best available original document. 


\title{
EMISSION, PLASMA FORMATION, AND BRIGHTNESS OF A PZT FERROELECTRIC CATHODE*
}

\author{
S. Sampayan, G. Caporaso, D. Trimble, and G. Westenskow, \\ Lawrence Livermore National Laboratory, Livermore, CA 94551 USA
}

\begin{abstract}
We have measured an $36-\mathrm{A}-\mathrm{cm}^{-2}$ current emission density over the surface area of an $11.4-\mathrm{cm}^{2}$-area Lead-Titanate-Zirconate (PZT) ferroelectric cathode with a pulsed anode-cathode (A-K) potential of $50 \mathrm{kV}$. We have also observed currents above those predicted by classical Child-Langmuir formula for a wide variety of cases. Since a plasma within the A-K gap could also lead to increase current emission we are attempting to measure the properties of the plasma near the cathode surface at emission time. In other measurements, we have observed strong gap currents in the absence of an A-K potential. Further, we continue to make brightness measurements of the emitted beam and observe spatially non-uniform emission and large shot-to-shot variation. Measurements show individual beamlets with a brightness as high $10^{11} \mathrm{~A} \mathrm{~m}^{-2} \mathrm{rad}^{-2}$.
\end{abstract}

\section{INTRODUCTION}

Pulsed ferroelectric electron emission was observed as early as 1964 [1]. New materials have shown extremely high peak current densities $\left(>100 \mathrm{~A}-\mathrm{cm}^{-2}\right)$ and high brightness $\left(10^{11} \mathrm{~A}-\mathrm{m}^{-2}\right.$-rad $\left.{ }^{-2}\right)[2,3]$. Further, these emitters can be operated at non-UHV pressures, do not require elevated operating temperatures or a pulsed laser system, making them a potentially very attractive altemative to conventional cathode technology.

Pulsed electron emission from a ferroelectric results during a rapidly switched internal polarization change. The exact emission mechanism has not yet been unambiguously identified but is believed to result from the expulsion of charge stimulated by the large, uncompensated, bound charge generated during the induced polarization change $[2,4,5]$.

Ferroelectric emission has many unique properties which we have previously reviewed [5]. They are as follows: (1) emission is energetic and has been measured to be from $0.5-100 \mathrm{KeV}$ depending on switching method and material type, (2) emitted current densities are above those determined by the Child-Langmuir formula, (3) strong emission can occur from a switched material without an applied A-K potential, (4) the quality of the emitted beam

\footnotetext{
* The work was performed under the auspices of the U.S. Department of Energy by Lawrence Livermore National Laboratory under contract W-7405-ENG-48.
}

can be high: comparable to photoemitters, and (5) emission can take place over a wide pressure range from below $10^{-7}$ to above $10^{-3} \mathrm{~T}$.

\section{APPARATUS}

We have reported on our apparatus in a previous paper [6]. Briefly, the apparatus consists of an A-K diode gap, an anode mask and fast phosphor for brightness measurements. The brightness diagnostic was replaceable with a screen mesh and view port for recording gated images of the cathode. The entire vacuum system and housing was fabricated from stainless steel; ceramics were used as insulators. Turbo-molecular pumps were used throughout. Base pressures in the $10^{-7} \mathrm{~T}$ range were easily achieved and maintained.

Additional diagnostics included a nude ion gauge and biased Faraday Cup. The nude ion gauge, for detection of neutral bursts, was electrically shielded from the main A-K gap and placed normal to the axis of the test stand. The Faraday cup, for detecting ion or electron current and inferring plasma density, was also placed normal to the diode axis and eventually circumferentially around the entire A-K gap.

Pre-poled and lapped PZT ferroelectric disks were placed behind and in contact with a conductive grid connected to the cathode. This conductive grid was either a square mesh composed of $25 \mathrm{~mm}$ diameter tungsten wires spaced approximately $750 \mathrm{~mm}$ on centers or an evaporated gold grid consisting of either $90 \mathrm{~mm}$ wide conductors, $300 \mathrm{~mm}$ on centers, or $50 \mathrm{~mm}$ conductors $760 \mathrm{~mm}$ on centers. A rear planar electrode received a pulsed high voltage which defined the switching electric field.

Sample orientation was such that the bound positive charge (negative screening charge) was positioned toward the A-K gap. Sample dimensions were typically $1 \mathrm{~mm}$ thick and with a $5.1 \mathrm{~cm}$ diameter. All but the $3.8 \mathrm{~cm}$ diameter central area of the sample was apertured. The grid-emitter assembly was recessed into the cathode shroud approximately $0.23 \mathrm{~cm}$; the distance from the emitter surface to the anode was varied from approximately 0.6 to $2 \mathrm{~cm}$.

Brightness measurements were performed with an anode mask consisting of nine $50 \mathrm{~mm}$ holes; 5 equally spaced vertically and the remaining spaced equally horizontally. A fast phosphor, $\mathrm{ZnO}(\mathrm{Ga})$, was used to image 
the pattern after a $24.5 \mathrm{~cm}$ drift distance. Charging was eliminated with a conductive film placed over the phosphor substrate. An image-intensified, gated camera allowed observation of the phosphor image. Gate width used was typically $40 \mathrm{~ns}$.

To observe the luminosity on the surface of the ferroelectric cathode, the anode mask was replaced with a screen mesh and the phosphor coated window was replaced with a transparent viewport. Fast gated, on axis images of the cathode surface could then be captured during the induced polarization change and subsequent emission.

\section{EXPERIMENTAL RESULTS AND DISCUSSION}

We observed stronger emission from cathodes prepared with a fine wire grid placed in close contact with the surface than with thin evaporated conductors. Emission from the ferroelectric was generally achieved with a negative 1 to $1.5 \mathrm{kV}$ inversion pulse. A-K potential was varied from zero to approximately $60 \mathrm{kV}$. Typical voltage and current waveforms are shown in Fig. 1. Peak currents of approximately $36 \mathrm{~A}-\mathrm{cm}^{-2}$ over the $11.4 \mathrm{~cm}^{2}$ surface area were achieved during these measurements.

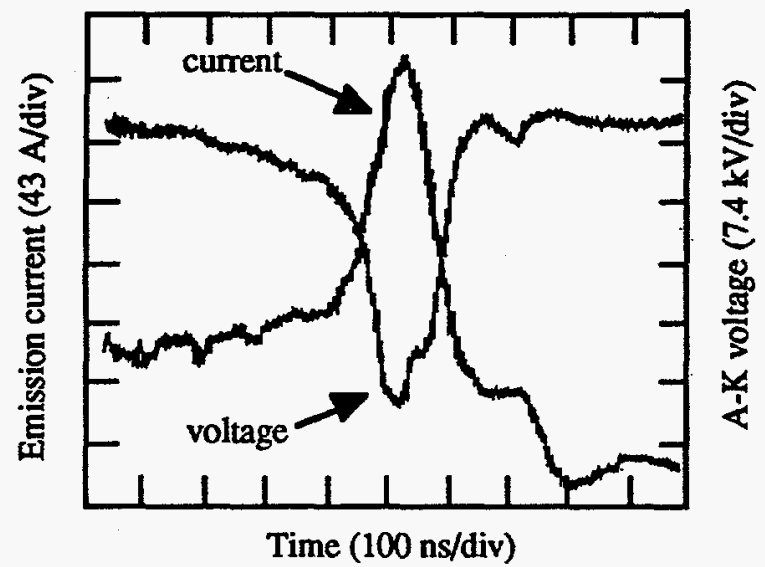

Figure 1. Typical current and A-K voltage pulse .

As was generally observed at lower A-K potentials, the measured current density, J, was unipolar, consistent with electron flow, and above the Child-Langmuir limit, $\mathrm{J}_{\mathrm{CL}}$, for electrons with zero initial kinetic energy (Fig. 2). In this data, the A-K potential was varied from $5 \mathrm{kV}$ to $50 \mathrm{kV}$, peak; the emitted current varied from $9.5 \mathrm{~A}$ to $411 \mathrm{~A}$, peak. The data indicated that the emitted current exceeded $\mathrm{J}_{\mathrm{CL}}$ at lower A-K potentials. The largest ratio of $\mathrm{J} / \mathrm{J}$, occurred at low potentials, on average, with much decreased ratios at increased potentials. As we previously described, the increased currents at low A-K potentials is believed to result from the electrons being emitted from the surface with significant kinetic energy [6].

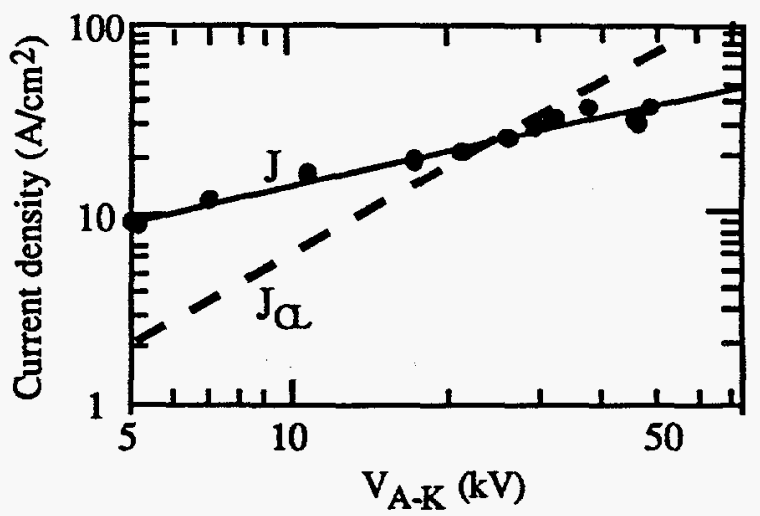

Figure 2. V-I characteristics for a 0.6-cm A-K gap.

With our present switching mode, e.g., maintaining the electric field on the ferroelectric until emission occurs, we have also observed on some samples strong emission (of

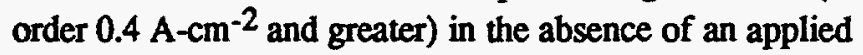
A-K potential (Fig. 3). Under the assumption that this electron emission is distributed uniformly over the cathode surface, a kinetic energy of over $3 \mathrm{KeV}$ was implied from this data.

During application of the inversion pulse we characteristically observed visible light from the emitter surface. With a gated camera, we correlated this luminosity to the application of the high voltage pulse used to induce a polarization change. In this measurement, strong luminosity is present on the emitter surface from the initiation of the inversion current pulse until cessation; strong correlation to the emitted current pulse, however, was not observed. By contrast, we generally observed strong luminosity from samples that had been strongly poled. Strong electron emission, however, did not always accompany this luminosity with or without an applied A-K pulse.

In these experiments, we have also sought to determine the existence of an expanding cathode plasma. From the

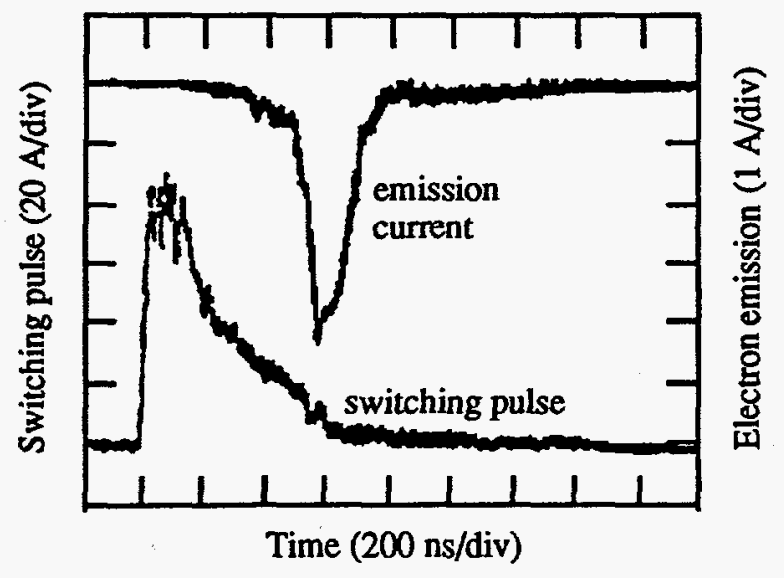

Figure 3. Emission without an applied A-K potential. 
data presented in Fig. 2, the existence of this plasma should manifest itself as a change in the gap perveance. From the Child-Langmuir equation, the slope of a plot of the squareroot of the inverse of the diode perveance (or the equivalent diode gap) as a function of time would be directly proportional to the plasma velocity [7]. In this data (Fig. 4), we observe no such slope indicating the existence of a stagnated plasma [8] or a plasma so tenuous that the emission in the diode gap was not affected.

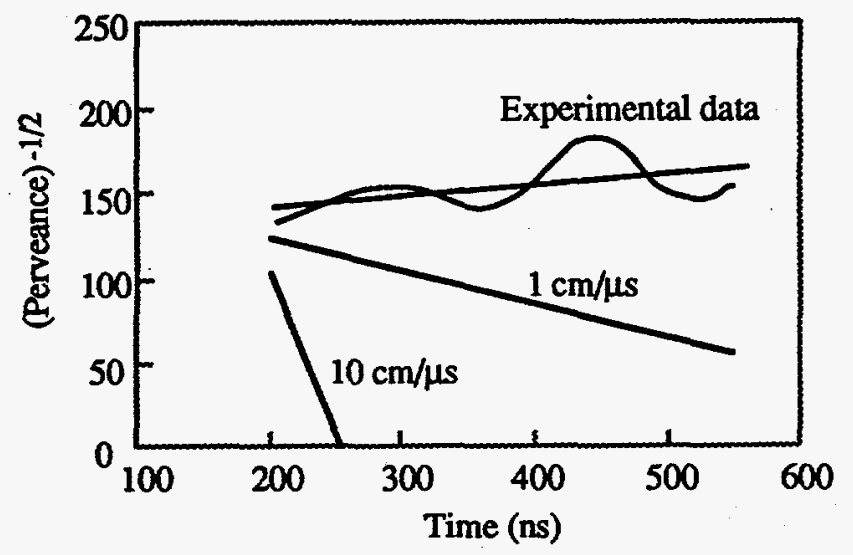

Figure 4. Effective gap during emission pulse.

In an additional attempt to determine the existence of a cathode plasma during emission without an A-K potential, a biased Faraday Cup collector transverse to the emitter axis was implemented. With a detection threshold of $0.25 \mathrm{~mA}^{-\mathrm{cm}^{-2}}$, no ion current was observed. Further, significant neutral bursts, as could be detected by the ion-gauge, were also not observed. From the observed emission current of $0.4 \mathrm{~A}-\mathrm{cm}^{-2}$ and the necessary cathode plasma density for such emission to take place, this detection threshold should have been more than adequate to detect the existence of ions from such a plasma.

Brightness measurements were accomplished with the multi-aperture mask previously described. In general, we observed distortion of the mask pattern on the phosphor and variation shot-to-shot.

In our particular geometry, the phosphor subtends an area of about $1 \mathrm{~mm}^{2}$ on the cathode surface. On a given shot, we sometimes observed faint multiple images of a single anode mask hole projected onto the phosphor. This observation strongly suggested that non-uniform, multiple emission sites, within areas of order $1 \mathrm{~mm}^{2}$, exist on the cathode surface and appear to be consistent with other ferroelectric emission processes described [9]. From typical data, we observed a divergence of $6.4 \mathrm{mrad}$ at a current density of $18{\mathrm{~A}-\mathrm{cm}^{-2}}^{-2}$ and energy of $33 \mathrm{KeV}$. From this data, as in previous calculations [6], we set a lower bound on the brightness of the individual beamlets as $10^{11} \mathrm{~A} \mathrm{~m}^{-2} \mathrm{rad}^{-2}$.

\section{SUMMARY}

We observed emitted current densities greater than those that would be predicted by the Child-Langmuir formula which assumes that electrons are emitted with zero initial energy. The existence of an interelectrode plasma, perhaps responsible for this result, was not evident in our measurements to date. Emission in the absence of an applied A-K potential was also observed. Observed surface luminosity did not correlate to electron emission nor did the luminosity always indicate the presence of emission. Measurement of the expansion of the individual beamlets yield a brightness of order $10^{11} \mathrm{~A}-\mathrm{m}^{-2} \mathrm{rad}^{-2}$. We continue to optimize the grid structure of the emitter and will attempt to stabilize the emission processes with reset and fine grain structure ferroelectric materials.

\section{REFERENCES}

[1] L. Belayev, G. Bendrikova, Fiz. Tverdogo, 6 (1964) 645 .

[2] H. Gundel, H. Riege, J. Handerek, and K. Zioutas, CERN Report No. CERN/PS/88-66 (AR), 1988.

[3] G. Kirkman, B. Jiang, and N. Reinhardt, presented at the IEEE International Electron Devices Meeting, San Francisco, California, 1992 (IEEE, New York). 1904.

[4] G. Rozenman and I. Rez, J. Appl. Phys., 73 (1993)

[5] S. Sampayan, G. Caporaso, W. Orvis, and T. Wieskamp, submitted to J. Vac. Sci. and Technology and as UCRL-JC-120507.

[6] S. Sampayan, G. Caporaso, C. Holmes, E. Lauer, D. Prosnitz, D. Trimble, and G. Westenskow, Nucl. Instr. and Methods, A340 (1994) 90.

[7] R. Parker, R. Anderson, and C. Duncan, J. Appl. Phys., 45 (1974) 2463.

[8] R. Shefer, L. Friedland, R. Klinkowstein, Phys. Fluids, 31 (1988) 930.

[9] B. Rosenblum, P. Braunlich, and J. Carrio, Appl. Phys. Lett., 25 (1974) 17. 